\title{
Fomes (Polyporales, Basidiomycota): medicinal, economic and ecological importance
}

\author{
Wang $\mathrm{H}$ and Zhao $\mathrm{CL}^{*}$
}

College of Biodiversity Conservation, Southwest Forestry University, Kunming 650224, P.R. China

Wang H and Zhao CL 2021 - Fomes (Polyporales, Basidiomycota): medicinal, economic and ecological importance. Fungal Biotec 1(2), 1-9, Doi 10.5943/FunBiotec/1/2/1

\begin{abstract}
Fomes have attracted much attention because of their important ecological, economic and medical values. In forest ecosystems, Fomes play a core role in promoting the circulation of nutrients and the flow of energy. In the application of modern medicine and biotechnology, the effective substances extracted from Fomes also have a great economic value. The aims of this review are to (1) review the historical taxonomy of Fomes, (2) briefly describe important species of Fomes together with their distribution, and (3) discuss the economic value of Fomes.
\end{abstract}

Keywords - Health benefits - Polyporaceae - Taxonomy - Wood-rotting fungi

\section{Introduction}

Fungi are an ecologically important branch of the tree of life based on its distinct and diverse characteristics, in which these organisms play a vital role in ecosystems. Fungi are found in soil, forests, rocks, and ocean, but their roles are primarily enacted behind the scenes, literally as hidden layers within their substrate (James et al. 2020). Taxonomy plays a central role in understanding the diversity of life, discovering into systems of names that capture the relationships between species, and translating the products of biological exploration (Hibbett 2016, Cui et al. 2019, James et al. 2020).

Polyporales is now well accepted and strongly supported order of Agaricomycetes and one of the most intensively studied groups of fungi, in which fungal ecologists and applied scientists are focusing on many taxa of this order (Hibbett et al. 2014, Justo et al. 2017, James et al. 2020). These taxa play a key role as food, enzymes and medicine, based on their important and potential applications in biomedical engineering and biodegradation (Dai et al. 2009, Levin et al. 2016, Bankole et al. 2020). Among 1,589 genera and 30,000 accepted species of Basidiomycota, roughly 1,800 species belong to Polyporales and its accounts only about $1.5 \%$ of all known species of fungi (Kirk et al. 2008). Polyporales were sampled extensively in phylogenetic studies using ribosomal RNA (rRNA) genes (Hibbett \& Vilgalys 1993, Hibbett \& Donoghue 1995, Larsson et al. 2004, Binder et al. 2005). From such analyses, four informally named clades of Polyporales were recognized: antrodia clade, core polyporoid clade, phlebioid clade and residual polyporoid clade. Addition of protein-coding genes, including RNA polymerase II subunit 2 ( $r p b 2$ ), and translation elongation factor 1-a (tefl) are necessary to achieve strong support for monophyly of Polyporales as a whole, and many internal nodes (Matheny et al. 2007, James et al. 2020).

The genus Fomes (Fr.) Fr. was proposed by Fries (1849) typified with $F$. fomentarius (L.) Fr, which was readily recognized by the non-specialist because of the layering of the tubes (Lowe 
1957). The original definition of the genus Fomes was broad and inaccurate, but the actual concept of the genus Fomes s. str. includes comparatively low species diversity (Justo et al. 2017). Macromorphically, this genus is characterized by the perennial, sessile, ungulate basidiomata with a gray to blackish pileus surface (Fig. 1); a smooth, hard crust and pale brown pore surface with small pores; regular, brown tube layers, and pale brown, tough-fibrous context (Fig. 2). Micromorphically, it can be characterized by a trimitic hyphal structure with clamps on generative hyphae, in which, the skeletal hyphae show pale brownish pigment in $\mathrm{KOH}$, and presence of the sclereids, and fusoid cystidioles, imbedded or projecting slightly, clavate basidia, four-celled, with a basal clamp (Fig. 3), and cylindrical basidiospores, colorless, smooth, inamyloid or negative in Melzer's reagent (Gilbertson \& Ryvarden 1987). Additionally, this genus causes white rot of living or dead hardwoods (Gilbertson \& Ryvarden 1987). The macroscopic characteristics most useful in identifying species in this genus are the size, shape, and comparative weight of the basidiomata, size of the pore, color and texture of context, and texture and distinctness of tube layers (Lowe 1957).

According to Index Fungorum (http://www. indexfungorum.org/, accessed $1^{\text {st }}$ June, 2021), 48 species have been accepted in the genus worldwide. Currently, the species $F$. fomentarius is a hot topic (Grand \& Vernia 2005, Júdová et al. 2012, McCormick et al. 2013).
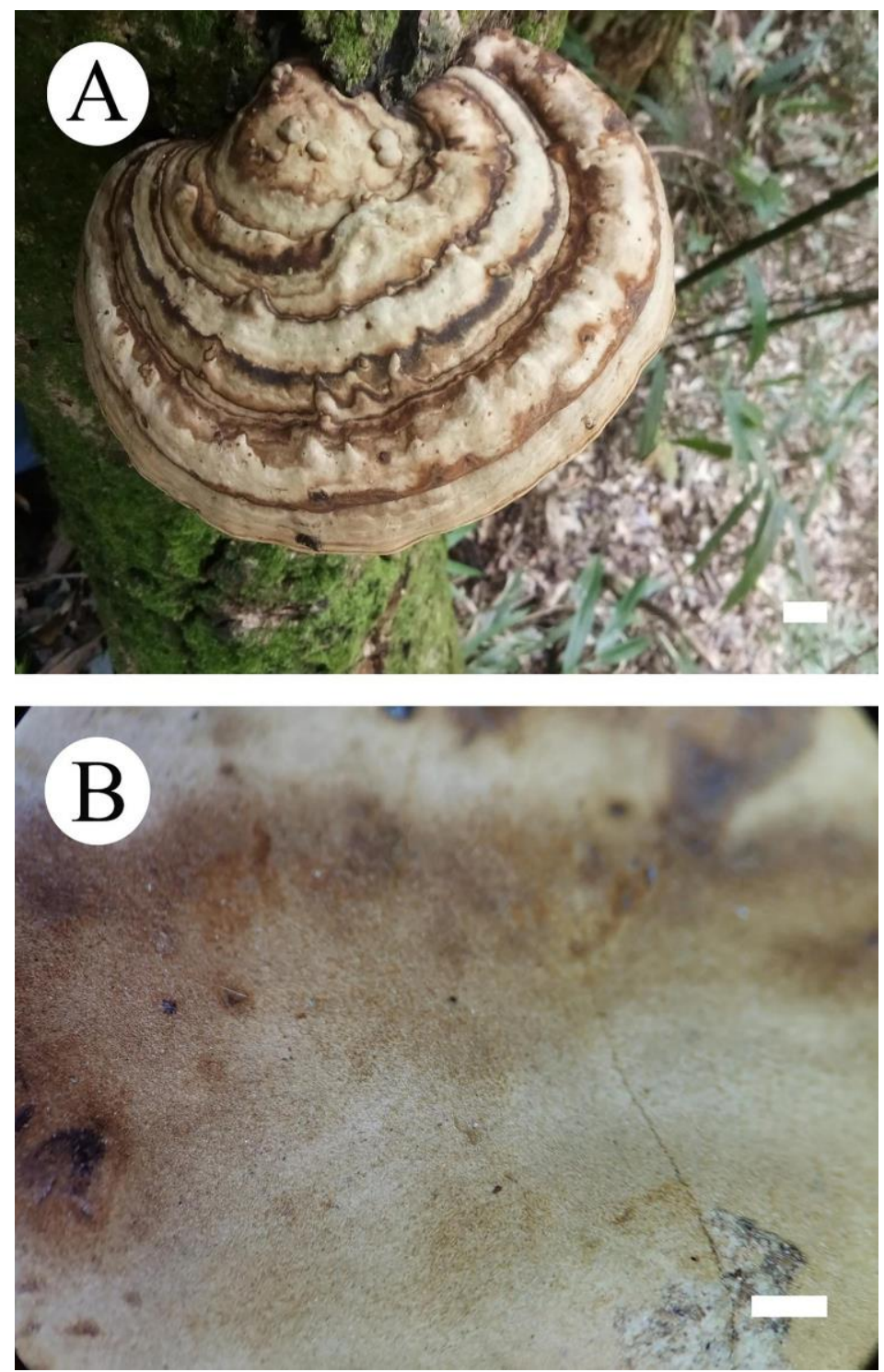

Fig 1. Basidiomata of Fomes fomentarius A-B. The upper surface of the basidiomata. Bars: A=1 $\mathrm{cm} ; \mathrm{B}=1 \mathrm{~mm}$. 

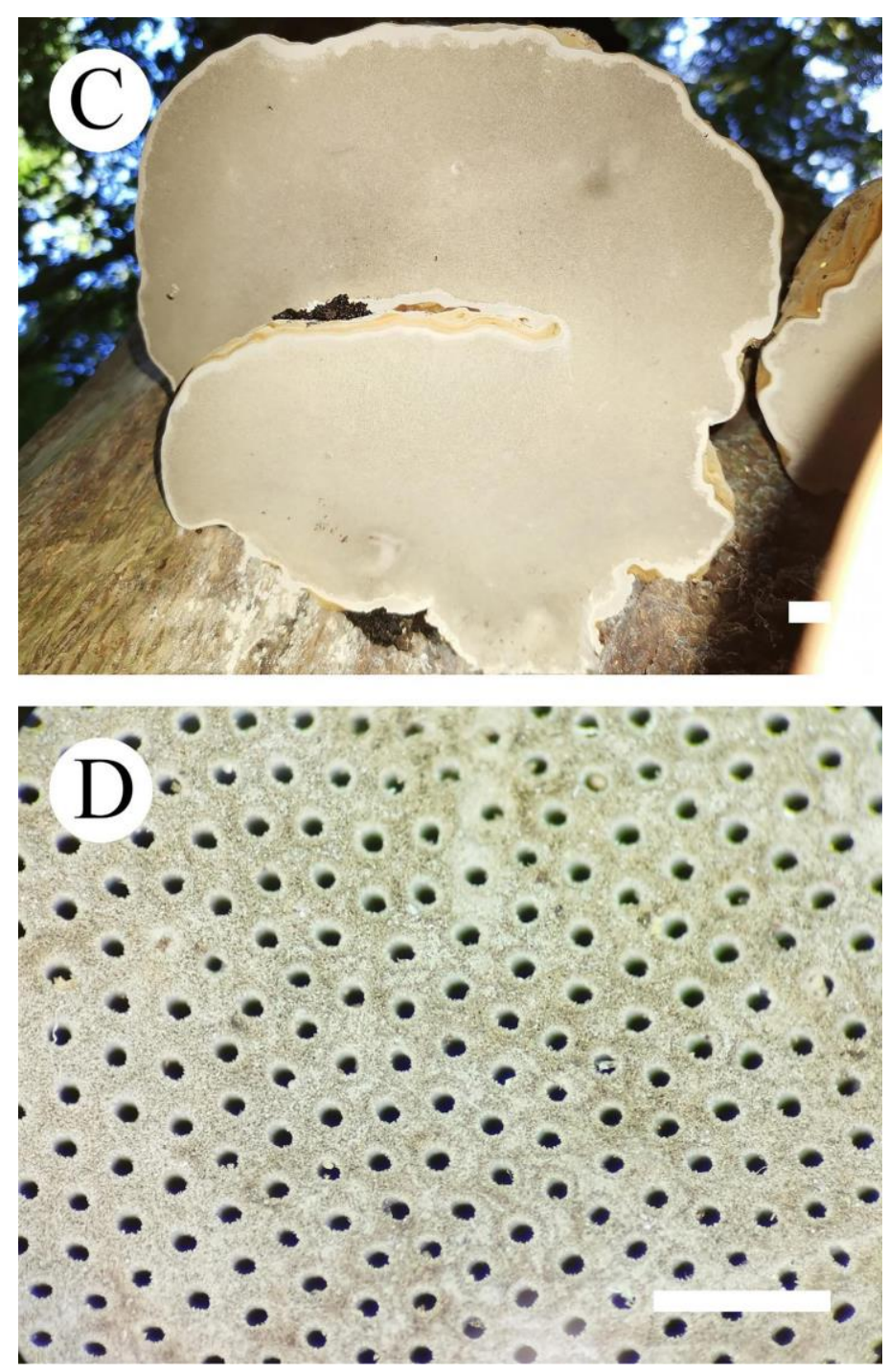

Fig 2. Basidiomata of Fomes fomentarius C. The lower surface of the basidiomata; D. A section of hymenophore. Bars: $\mathrm{C}=1 \mathrm{~cm} ; \mathrm{D}=1 \mathrm{~mm}$.

\section{Morphological studies of Fomes}

Until the late 1980s, the taxa of polypores have been described mostly based on their macromorphological and micro-morphological characteristics. The simple morphology of fungal structures (e.g., hyphae, spores, basidiomata), polypore diversity, and the lack of a useful fossil record have been major impediments to progress in this field (Júdová et al. 2012). The research showed that the genus Fomes was similar in its morphology to Polyporus P. Micheli ex Adans., Poria P. Browne, and Trametes Fr., but there can be no absolute demarcation of these genera, and three new combinations based on morphological studies: $F$. jobnsonianus (Murrill) J. Lowe, $F$. santic-georgii (Pat.) J. Lowe and F. viticola (Schwein.) J. Lowe were proposed (Lowe 1957). In the study of Gilbertson \& Ryvarden (1986), it was found that the genus Fomes is well characterized by its perennial basidiomata, which have a conspicuous mycelial granular core close to the substratum, consisting of very thick-walled and irregularly shaped hyphae. The granular core instantaneously separated this genus from other similar genera that may or may not be closely related (Gilbertson \& Ryvarden 1986). In the early part of the 20th century, several hundreds of specific epithets were associated with this generic name, in which most of these species have been gradually shown to belong in other genera, thus the most recent concept of the genus was incomparably narrower and it comprised two different morphological species, $F$. fomentarius and $F$. fasciatus (Sw.) Cooke, in addition to some cryptic species within this group of strains (Ryvarden 1991). Nevertheless, both species $F$. fomentarius and $F$. fasciatus shared many morphological traits that historically have 
made species delimitation challenging (Júdová et al. 2012). Based on similarities in the basidiomata morphology of $F$. fomentarius and $F$. fasciatus, mycologists reported that basidiomata of $F$. fomentarius tended to be more consistently ungulate and typically have a concave pore surface, but $F$. fasciatus basidiomata vary greatly from applanate to ungulate and generally have a convex pore surface (Murrill 1915, Ryvarden \& Gilbertson 1993). The results showed that $F$. fomentarius basidiomata produce larger basidiospores $(12-18 \times 4-7 \mu \mathrm{m})$, whereas $F$. fasciatus has smaller basidiospores (12-14 × 4-4.5 $\mu \mathrm{m}$, Ryvarden \& Gilbertson 1993). A few years later, research reported evidence of the conidial stages in the development of primary and dikaryotic mycelia of $F$. fomentarius, in which the experiments focused on the viability and the dynamics of basidiospore germination, primary and dikaryotic mycelia growth, conidia development of $F$. fomentarius and proposed a new model of their life cycles (Mukhin \& Votintseva 2002). In recent years, the researches focused on the tinder polypore mushroom $F$. fomentarius, within medicinal fungal species and their implications for morphological variability, physiological activity, biochemical variability, and geographic ecology, in which the species epithet $F$. fomentarius had often misleadingly been used for 2 closely related species: $F$. fomentarius and $F$. fasciatus and both species were principally separated from one another by the mean basidiospore size (Gáper et al. 2016). The detailed examination of a number of different Fomes strains had been collected and isolated from different habitats in Italy and Austria, which confirmed the presence of distinct lineages in F. fomentarius clade, additionally, in their study, they also showed that physiological characteristics were species-specific properties, in which the daily mycelial growth rates or the temperature range of pure cultures and the production of VOCs could be considered as a very promising tool for fast and reliable species delimitation in the future (Peintner et al. 2019).
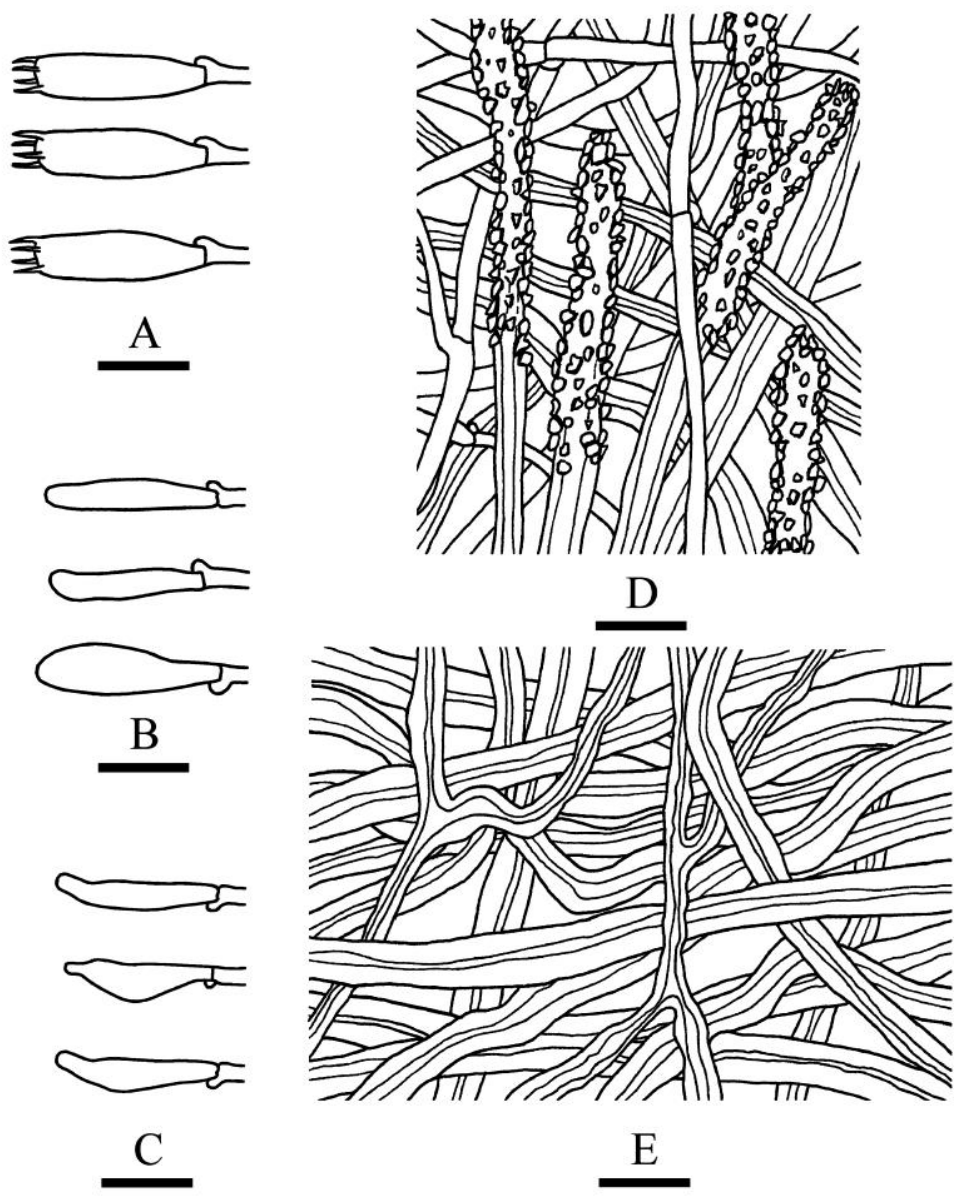

$\mathrm{E}$

Fig 3. Microscopic structures of Fomes fomentarius A. Basidia; B. Basidioles; C. Cystidioles; D. Hyphae from trama; E. Hyphae from context. Bars: A-E=10 $\mu \mathrm{m}$. 


\section{Molecular systematics of Fomes}

In the middle of 1990s, the evolutionary based species concepts began to occur (Hibbett \& Donoghue 1995, Boidin et al. 1998). The use of population tools and DNA-based methods for the identification of taxa emerged, and especially rDNA genes have been successfully used as a target for species identification in taxonomic, evolutionary, and environmental studies of fungi (Borneman \& Hartin 2000, Chase \& Fay 2009). Most studies focused on the internal transcribed spacer (ITS) region located between rRNA structural genes in the rDNA cistron, in which this approach was widely used for identification of many eukaryotic specimens, including fungi (Anderson \& Cairney 2004, Naumann et al. 2007, Justo et al. 2017, Zhao \& Zhao 2021).

In the middle of the 19th century, the genus Fomes was proposed as a polyphyletic group in several analyses of mitochondrial small-subunit (mt-ssu) ribosomal DNA (rDNA) or mt-ssu rDNA and nuclear small-subunit rDNA (Gáper et al. 2016). Fomes was determined to be monophyletic in phylogenetic analyses of nuclear and mitochondrial large- and small-subunit rDNAs, but support for this group was weak in these analyses (Gáper et al. 2016). Fomes fomentarius had been considered a homogeneous species, in which the existence of two lineages was revealed based on ITS sequence variability (Júdová et al. 2012). A study found evidence suggesting the presence of a third group within the North American strains of $F$. fomentarius (McCormick et al. 2013). An analysis using sequence data from nuclear and mitochondrial large- and small-subunit rDNAs from 91 species of homobasidiomycetes revealed that Fomes grouped with other polypores, which had a similar characteristic of the trimitic hyphal system (Hibbett et al. 2014). The phylogenetic tree distinguished a fourth group within $F$. fomentarius from China (Dresch et al. 2015). Based on the comparison of ITS sequences, three different lineages and sublineages in $F$. fomentarius were clearly identified (Gáper et al. 2016).

\section{Economic importance}

The importance of biodiversity and biogeography of fungi, especially in unique ecosystems and specific regions, was previously addressed by Grand \& Vernia (2005). Fungi of the Fomes are the traditional morphological polypore genus, almost found on broad-leaved forest trees, and cause wood rot, and play a highly beneficial role in slash disposal (Júdová et al. 2012). On the other hand, many species under favorable conditions, attacking standing timber, causing heart rot and decaying wood products (Júdová et al. 2012, Hibbett et al. 2016, James et al. 2020). Though the economic loss from wood decay is large, it should be remembered that the harmful decay was a minor part of the indispensable and vastly beneficial cyclic process that replenishes carbon dioxide and other substances essential for green plant growth, which in turn supports all animal existence (Lowe 1957, Pozzi et al. 2020). In natural ecosystems, they have ecological functions such as nutrient cycle and providing insects with nesting holes and shelters (Gilbertson 1980, Makinen et al. 2019, Gonzalez et al. 2020).

Fomes not only act as reductors in nature, but also rely on resources of early people, and its extracted substances are of great value in modern medical treatments (Lowe 1957). The perennial bracket fungi, because of their size and persistence, have attracted attention from very early times, and the medicinal value soon brought specific recognition to $F$. officinalis, which was well-known to the Greeks and the Romans (Lowe 1957). The 5000-year-old Neolithic man was the first to apply tinder material prepared from genus $F$. basidiomata for medicinal purposes in a first aid kit (Peintner et al. 1998, Pöder \& Peintner 1999). So far, the study of fungi of Fomes has been a hot topic, in which its extracts have remarkable efficacy on some diseases, and have great potential and economic value in modern medicine, bio-pharmaceuticals and applications (Suriya 2020, Kalitukha 2021, Liudmila \& Miriam 2021).

\section{Ecology and distribution}

The genus Fomes are widely distributed in Africa, Asia, Europe and North America. For example, $F$. fomentarius is very common and widespread in all habitat zones of the West Siberian Plain, whose forest vegetation was shaped mainly by climate (Mukhin \& Votintsevav 2002, Júdová 
et al. 2012). The valid distribution records depend upon accurate determination of specimens and the species in the North Temperate Zone are usually those long known by tradition, or adequately represented by type material, the identity of each of these is clear and its distribution quite certain (Lowe 1957). Tropical species, are often known from scanty material, and are frequently represented by sterile types; in contrast, the distribution of tropical species is hazy (Lowe 1957).

\section{Important species and applications of Fomes}

Fomes fomentarius is the traditional morphological polypore species, and it is almost always found on broad-leaved forest trees, where it causes white rot (McDonald 1938). This very common fungus is distributed within the northern hemisphere in North America, North Africa, Asia, and all over Europe (McDonald 1938, Breitenbach \& Kränzlin 1986, Kotlaba 1997). This is commonly known as the "tinder fungus", "hoof fungus", "tinder conk", "tinder polypore", or "Iceman's fungus" (Peintner et al. 2019). Besides the widespread and important use as tinder, F. fomentarius was a valued medicinal polypore in European traditional medicine (Killermann 1938). The 5000year-old Iceman probably used this polypore to make and preserve fire, as a first aid kit, an insect repellent, or for spiritual purposes (Peintner et al. 1998, Pöder \& Peintner 1999). It is first mentioned date back to the times of Hippocrates, who reported its topical use for cauterizing wounds and for externally treating inflamed organs (Pöder 2005). In the medieval times, it is use in in Europe and Western Siberia as a styptic and it was prescribed as a remedy against dysmenorrhea, hemorrhoids, and bladder disorders, the active substance being "fomitin" and used as a hemostatic dressing and ban-dage to maintain body temperature and compress parts of the body (Killermann 1938). Stretched stripes or smaller pieces were used as a remedy against bleeding wounds and for various skins injures, and it therefore was called "agaric of surgeons" "Chirurgenschwamm" "Wundschwamm" or "Fungus chirurgorum" (Roussel et al. 2002). The basidiomata have been used as a traditional medicine for centuries in China and Korea in treating various diseases such as gastroenteritic disorder, hepatocirrhosis, oral ulcer, inflammation, and various cancers (Cheng et al. 2000, Chen et al. 2008, Huang et al. 2012, Gáper et al. 2016, Bari et al. 2021).

\section{Acknowledgements}

The research was funded by Yunnan Fundamental Research Project, grant number 202001AS070043 and Science Research Foundation of Yunnan Provincial Department of Education Project (Project No. 2021Y275).

\section{References}

Anderson I, Cairney J. 2004 - Diversity and ecology of soil fungal communities: increased understanding through the application of molecular techniques. Environmental Microbiology 6, 769e779. Doi 10.1111/j.1462-2920.2004.00675.x

Breitenbach J, Kränzlin F. 1986 - Fungi of Switzerland, vol. 2, Verlag Mykologia, Lucerne.

Bankole PO, Adedotun AA, Jeon BH, Govindwar SP. 2020 - Novel cobiomass degradation of NSAIDs by two wood rot fungi, Ganoderma applanatum and Laetiporus sulphureus: Ligninolytic enzymes induction, isotherm and kinetic studies. Ecotoxicology and Environmental Safety 203, 110997. Doi 10.1016/j.ecoenv.2020.110997

Bari E, Pizzi A, Schmidt O, Amirou S et al. 2021 - Differentiation of fungal destructive behaviour of wood by the white-rot fungus Fomes fomentarius by MALDI-TOF mass spectrometry. Journal of Renewable Materials 9, 3. Doi 10.32604/jrm.2021.015288

Binder M, Hibbett DS, Larsson KH, Larsson E, Langer E, 2005 - The phylogenetic distribution of resupinate forms in the homobasidiomycetes. Systematics and Biodiversity 3, 113e157.

Doi 10.1017/S1477200005001623

Boidin J, Mugnier J, Canales R. 1998 - Taxonomie moleculaire des Aphyllophorales. Mycotaxon $66,445 \mathrm{e} 491$. 
Borneman J, Hartin RJ. 2000 - PCR primers that amplify fungal rRNA genes from environmental samples. Applied and Environmental Microbiology 66, 4356e4360. Doi 10.1128/AEM.66.10.4356-4360.2000

Chase M, Fay M. 2009 - Barcoding of plants and fungi. Science 325, 682e683. Doi 10.1126/science. 1176906

Chen W, Zhao Z, Chen S, Li Y. 2008 - Optimization for the production of exopolysaccharide from Fomes fomentarius in submerged culture and its antitumor effect in vitro. Bioresour Technol 99, 3187-3194. Doi 10.1016/j.biortech.2007.05.049

Cheng DS, Yamaguchi T, Wang ZJ, Pan XR, 2000 - Genetic differentiation between two morphological types of Fomes fomentarius based on isozyme analysis. Mycosystema 19, $81 \mathrm{e} 86$.

Cui BK, Li HJ, Ji X, Zhou JL et al. 2019 - Species diversity, taxonomy and phylogeny of Polyporaceae (Basidiomycota) in China. Fungal Diversity 97, 137-392. Doi 10.1007/s13225019-00427-4

Dai YC, Yang ZL, Cui BK, Yu CJ, Zhou LW. 2009 - Species diversity and utilization of medicinal mushrooms and fungi in China (review). International Journal of Medicinal Mushrooms 11, 287-302. Doi 10.1615/IntJMedMushr.v11.i3.80

Dresch P, Aguano MN, Rosam K, Grienke U et al. 2015 - Fungal strain matters: colony growth and bioactivity of the European medicinal polypores Fomes fomentarius, Fomitopsis pinicola and Piptoporus betulinus. AMB Express 5, 1-14. Doi 10.1186/s13568-014-0093-0

Fries E. 1849 - Summa vegetabilium Scandinaviae. Sectio posterior [in Latin]. Stockholm (Sweden), A Bonnier.

Grand LF, Vernia CS. 2005 - Biogeography and hosts of poroid wood decay fungi in North Carolina: species of Fomes, Fomitopsis, Fomitella and Ganoderma. Mycotaxon 94, 231-234.

Gáper J, Gáperová S, Pristaš P, Náplavová K. 2016 - Medicinal value and taxonomy of the tinder polypore, Fomes fomentarius (Agaricomycetes): A review. International Journal of Medicinal Mushrooms 18, 851-859. Doi 10.1615/IntJMedMushrooms.v18.i10.10

Grand LF, Vernia CS. 2005 - Biogeography and hosts of poroid wood decay fungi in North Carolina: species of Coltricia, Coltriciella and Inonotus. Mycotaxon 91, 35-38.

Gilbertson RL. 1980 - Wood-rotting fungi of North America. Mycologia 72, 1-49. Doi 10.1080 /00275514.1980.12021153

Gilbertson RL, Ryvarden L. 1986-1987 - North American polypores 1-2. Fungifora, Oslo. Pp. 1433.

Gonzalez A, Corsini G, Lobos S, Seelenfreund D, Tello M. 2020 - Metabolic specialization and codon preference of lignocellulolytic genes in the white rot Basidiomycete Ceriporiopsis subvermispora. Genes 11, 1227. Doi 10.3390/genes11101227

Huang TZ, Du DY, Chen YQ, Yuan B et al. 2012 - Chemical constituents and antitumor activity of fruiting body of Fomes fomentarius [article in Chinese]. Mycosystema 31, 775-83.

Hibbett DS, Vilgalys R, 1993 - Phylogenetic relationships of Lentinus (Basidiomycotina) inferred from molecular and morphological characters. Systematic Botany 18, 409e433.

Hibbett DS, Donoghue MJ. 1995 - Progress toward a phylogenetic classification of the Polyporaceae through parsimony analyses of ribosomal DNA sequences. Canadian Journal of Botany 853e861. Doi 10.1139/b95-331

Hibbett DS, Bauer R, Binder M, Giachini AJ et al. 2014 - Agaricomycetes. In: McLaughlin DJ, Spatafora RJ, editors. The mycota: systematics and evolution part A. VII. 2nd ed. Heidelberg (Germany), Springer. Pp. 373-429. Doi 10.1007/978-3-642-55318-9_14

Hibbett DS. 2016 - The invisible dimension of fungal diversity. Science 351, 1150-1151. Doi 10.1126/science.aae 0380

Hibbett DS, Abarenkov K, Kõljalg U, Öpik M et al. 2016 - Sequence-based classification and identification of Fungi. Mycologia 108, 1049-1068.

James TY, Stajich JE, Hittinge CT, Rokas A. 2020 - Toward a fully resolved fungal tree of life. Annual Review of Microbiology 74, 1-23. Doi 10.1146/annurev-micro-022020-051835 
Justo A, Miettinen O, Floudas D, Ortiz-Santana B et al. 2017 - A revised family-level classification of the Polyporales (Basidiomycota). Fungal Biology 121, 798-824. Doi 10.1016/j.funbio.2017.05.010

Júdová J, Dubíková K, Gáperová S, Gáper J, Pristaš P. 2012 - The occurrence and rapid discrimination of Fomes fomentarius genotypes by ITS-RFLP analysis. Fungal Biology 116, 55-60. Doi 10.1016/j.funbio.2011.10.010

Kalitukha L. 2021 - An approach to change the basic polymer composition of the milled Fomes fomentarius fruiting bodies. Fungal Biology Biotechnology 8, 5. Doi 10.1186/s40694-02100112-9

Killermann S. 1938 - Ehemaliger apothekerpilz. Zeitschrift für Pilzkunde 22, 11-13.

Kirk PM, Cannon P.F, David JC, Minter DW, Stalpers JA. 2008 - Ainsworth and bisby's dictionary of the fungi, 10th edn. CAB International Press, Wallingford. Doi $10.1079 / 9780851998268.0000$

Kotlaba F. 1997 - Common po

lypores (Polyporales s.l.) collected on uncommon hosts. Czech Mycology 49, 169e188. Doi 10.1079/9780851998268.0000

Larsson KH, Larsson E, Kõljalg U, 2004 - High phylogenetic diversity among corticioid homobasidiomycetes. Mycological Research 108, 983e1002. Doi $10.1017 / \mathrm{S} 0953756204000851$

Levin L, Maira C, Martin H, Rene U. 2016 - Degradation of 4-nitrophenol by the white-rot polypore Trametes versicolor. International Biodeterioration \& Biodegradation 107, 174-179. Doi 10.1016/j.ibiod.2015.11.023

Liudmila K, Miriam S. 2021 - Chemical composition and ultraviolet absorption activity of an aqueous alkali extract from the fruiting bodies of the tinder conk mushroom, Fomes fomentarius (Agaricomycetes). International Journal of Medicinal Mushrooms 23, 23-37. Doi 10.1615/IntJMedMushrooms.2021038160

Lowe JL. 1957 - Polyporaceae of North America the genus Fomes. State University College of Forestry at Syracuse University, No. 80.

Matheny PB, Wang Z, Binder M, Curtis JM et al. 2007 - Contributions of rpb2 and tefl to the phylogeny of mushrooms and allies (Basidiomycota, Fungi). Molecular Phylogenetics and Evolution 43, 430e451. Doi 10.1016/j.ympev.2006.08.024

Makinen M, Kuuskeri J, Laine P, Smolander OP et al. 2019 - Genome description of Phlebia radiata 79 with comparative genomics analysis on lignocellulose decomposition machinery of phlebioid fungi. BMC Genomics 20, 430. Doi 10.1186/s12864-019-5817-8

McCormick MA, Grand FL, Post BJ, Cubeta MA. 2013 - Phylogenetic and phenotypic characterization of Fomes fasciatus and Fomes fomentarius in the United States. Mycologia 105, 24-34. Doi 10.3852/12-336

McDonald JA, 1938 - Fomes fomentarius (Linn) Gill (Ungulina fomentaria) on birch in Scotland. Transactions of the British Mycological Society 32, 396e408. Doi 10.1080/13594863809441531

Murrill WA. 1915 - Southern polypores. New York, Murril. Doi 10.5962/bhl.title.22920

Mukhin VA, Votintsevav AA. 2002 - Basidispore germination and conidial stages in the life cycles of Fomes fomentarius and Fomitopsis pinicola (Fungi, Polyporales). Polish Botanical Journal 47, 265-272.

Naumann A, Navarro-González M, Sánchez-Hernández O, Hoegger PJ, Kües U. 2007 - Correct identification of wood-inhabiting fungi by ITS analysis. Current Trends in Biotechnology and Pharmacy 1, 41e61.

Peintner U, Pöder R, Pümpel T. 1998 - The Iceman's fungi. Mycological Research 102, 1153-1162. Doi 10.1017/S0953756298006546

Peintner U, Kuhnert-Finkernagel R, Wille V, Biasioli F, Shiryaev A, Perini C. 2019 - How to resolve cryptic species of polypores: an example in Fomes. IMA Fungus 10, 17. Doi $10.1186 / \mathrm{s} 43008-019-0016-4$ 
Pozzi C, Rajchenberg M, Ojeda V. 2020 - Decay fungi associated with cavity excavation by a large South American woodpecker. Forest Pathology 50, e12634.

Pöder R, Peintner U. 1999 - Laxatives and the ice man. The Lancet 353, 926-926. Doi 10.1016/S0140-6736(05)75032-7

Pöder R. 2005 - The Ice Man's fungi: facts and mysteries. Int J Med Mushrooms 7, 37-59. Doi 10.1615/IntJMedMushr.v7.i3.190

Ryvarden L. 1991 - Genera of polypores, nomenclature and taxonomy. Synopsis Fungorum 5, Oslo, Fungiflora.

Ryvarden L, Gilbertson RL. 1993 - European polypores. Part 1. Synopsis Fungorum 5, Oslo, Fungiflora.

Roussel B, Rapior S, Charlot C, Masson CL, Boutié P. 2002 - History of the therapeutic uses of the tinder polypore, Fomes fomentarius (L.): Fr. [article in French]. Revue Histoire de la Pharmacie 50, 599-614. Doi 10.3406/pharm.2002.5432

Suriya R, Romana F, Rabindran J, Sarah Mousa A et al. 2020 - A wild Fomes fomentarius for bomediation of one pot synthesis of titanium oxide and silver nanoparticles for antibacterial and anticancer application. Biomolecules 10, 622. Doi 10.3390/biom10040622

Zhao W, Zhao CL. 2021 - The Phylogenetic relationship revealed three new wood-inhabiting fungal species from genus Trechispora. Frontiers in Microbiology 12, 650195. Doi 10.3389/fmicb.2021.650195 